\title{
State of the Art Vibration Analysis of Electrical Rotating
}

\section{Machines}

\author{
Israr Ullah ${ }^{1}$, Naeem Arbab $^{1}$ and Waheed Gul $^{2}$ \\ 1. Department of Electrical Engineering, University of Engineering and Technology, Peshawar 25000, Pakistan \\ 2. Department of Mechanical Technology, University of Technology, Nowshera 24110, Pakistan
}

\begin{abstract}
Electrical machines are precarious mechanisms in manufacturing practices. A motor failure may yield an unexpected interruption at the industrial plant, with consequences in costs, product quality, and security. To govern the conditions of each part of motor, various testing and monitoring methods have been developed. In this paper, a review on effective fault indicators and vibration based condition monitoring approaches of rotating electrical machines has been accomplished. The determination of the review is to progress the understanding of vibration based analysis, and its use in the Machine Health Monitoring. A variety of analysis was identified to highlight the concept of predictive maintenance in industries. The techniques of vibration analysis were investigated to detect both healthy and fault related signals of rotating machineries.
\end{abstract}

Key words: Machine health monitoring, vibration analysis, time domain, frequency domain.

\section{Introduction}

Vibration monitoring of electrical machines is one of the stimulating tasks for researchers essentially in manufacturing units. There are numerous condition monitoring approaches, containing Vibration monitoring, thermal monitoring, chemical monitoring and acoustic emission monitoring [1]. Vibration monitoring is accompanied to support in the assessment of the well-being of the machine throughout nonstop operation. It has been revealed several times over that the vibration signature of a working machine should be responsible for additional statistics about the inner mechanisms of the machine than any other sort of non-destructive test. A bearing that has a minor emerging defect will cause a betraying change in the machine vibration, as well an imbalance condition, a misalignment, or any of an innumerable of additional faults. Vibration analysis accurately applied to Predictive Maintenance, permits the technician to identify trivial emerging mechanical flaws extended before they become a risk to the

Corresponding author: Israr Ullah, research scholar, research field: machine health monitoring. reliability of the machine, and thus delivers the essential lead-time to calendar maintenance to ensemble the requirements of the plant supervision. In this way, plant supervision has governed over the machines, relatively than the other way everywhere. Vibration measurement and analysis is the foundation of Predictive Maintenance, which stances in shrill disparity to the ancient "run-to-failure" type of maintenance practice. Copious studies, such as those accompanied by the EPRI (Electric Power Research Institute), have presented that on usual, the cost to industry for maintenance will be condensed by more than $50 \%$ if a predictive maintenance package is used as a replacement for of run-to-failure [2].

The practice of vibration analysis as one of the major tackles for condition monitoring has been industrialized comprehensively over a period of just about 35 years. With the corresponding expansions in electronic equipment, transducers, computers and software currently machine management is nearly entirely mechanized. From 1960 to the mid-1970s simple concrete approaches were used, along with cautious guard on the machine's performance, often 
armored by recurrent maintenance. Fundamental tools were occasionally used to quota and record the values on which letdown detection and clinched maintenance verdicts were based. Though nearly digital tools were accessible during the early 1970s, momentous expansions took place for the duration of the late 1970s and the early 1980s due to the accessibility of new microprocessors [3]. Circuits could be shrunken, plummeting the proportions and weight of apparatuses and permissible data to be fingered at high speeds. Onboard microprocessors gave instruments the capability to seizure data, examine it via suitable algorithms, then stock and display the information. A very substantial feature of frequency analysis was effective computation of the FFT (Fast-Fourier-Transformation) of multi-channel measurements within seconds correspondingly minutes and the capability to store data for further conclusions. Long-term data storage became a putative practice. From the mid-1980s forward the expansions have been related with the desktop computer, its interfaced apparatus and software, which permit the entire process and the real machine condition to be examined automatically, giving a comprehensive provision for measurement, analysis and problem diagnosis trailed by action or maintenance approaches. The 1990s are considered by lessening the instrumentation and the data acquisitions and data process units. Sensors systems are joined with electronic data pre-processing and multi-sensor agreement allow not only accentuating on single machine mechanisms, the entire plant with the connections and enslavements of all procedures become translucent, though vibration analysis was used previous essentially to govern faults and perilous operation circumstances. At the present time the anxieties for condition monitoring and vibration analysis are no more inadequate annoying to curtail the penalties of machine failures, but to exploit current resources more efficiently.

To stare at an electrical signal, we use an oscilloscope to realize how the signal varies with time. This is very significant information; yet, it does not provide us the full image. To, fully recognize the performance of a scheme or device, we also want to investigate the signal in the frequency domain. This is a graphical illustration of the signal's amplitude as a function of frequency. The spectrum analyzer is to the frequency domain as the oscilloscope is to the time domain. The amplitude of the frequency at the machines running rpm and its different harmonics is patterned. Any amplitude beyond a threshold value clues toward a particular fault. The diagnosis of fault before a major break takes place is the aim of preventive maintenance. In addition to frequency domain analysis, the spectrum analyzer has the capability to accomplish time domain analysis by the statistical time values and their tendency of settings and, spectrum analysis to enumerate periodical information of spectral data [4].

\section{Vibration Monitoring}

All electrical machines produce noise and vibration, and the analysis of the generated noise and vibration can be used to give statistics on the condition of machine. Even very minor amplitude of vibration of machine frame can generate high noise. The vibration of electrical machines is consummated through the use of broad-band, narrow-band or signature analysis of the calculated vibration energy of the machine. Monitoring of vibration based judgement is the best technique for fault diagnoses.

Use of fiber optics based sensors approach in Refs. $[4,5]$ for different types of vibration signals monitoring is found relatively cost effective. Also it provides an easy way of measuring vibration signals up to some extent. Neha and Sakshi [4] carried out an innovative fiber optic vibration sensor for health monitoring of electrical machines, which operates with comparatively unpretentious technologies and offers reasonable costs. The sensor is enhanced for revealing of mechanical vibrations in the frequency 
range $20-100 \mathrm{~Hz}$ and amplitude in the range of 2-6 $\mathrm{mV}$. The design and construction of the sensor is shown in Fig. 1.

From experimental setup the vibrations of a loud speaker were measured. The speaker input was from signal generator and frequency was speckled to attain altered levels of vibration of the speaker. The vibration sensor was fastened on to the speaker and one fiber of the bifurcated fiber was linked to an optical power meter, the Led of which formed the light source. The light subsequently reflected from the mirror came in the second fiber which was coupled to an optical to electrical converter. The output of the $\mathrm{O} / \mathrm{E}$ converter was given to CRO where the waveform of the yield vibration amplitude and frequency was achieved. The speaker used was an $8 \mathrm{Ohm}$; frequency used was $100 \mathrm{~Hz}$ and was varied with a frequency multiplier. It was experientially noted that with decrease of frequency the amplitude of vibration also acquires reduced ensuing into smooth vibrations. It was observed that the quantity of light engrossed and conveyed was significantly improved by using a plastic fiber of superior thickness and the occurrence power on the fiber was improved to $30 \mathrm{db}$ by the use of multimode plastic fiber of $1 \mathrm{~mm}$ diameter instead of silica fiber of thickness 80/125 microns. Any vibration which could rebound the mirror up to this distance could be measured. The differences of the space measured in above experiment are given in Fig. 2. It can be seen that as the comparative distance between the mirror and the fiber probe reduces, the power measured increases.

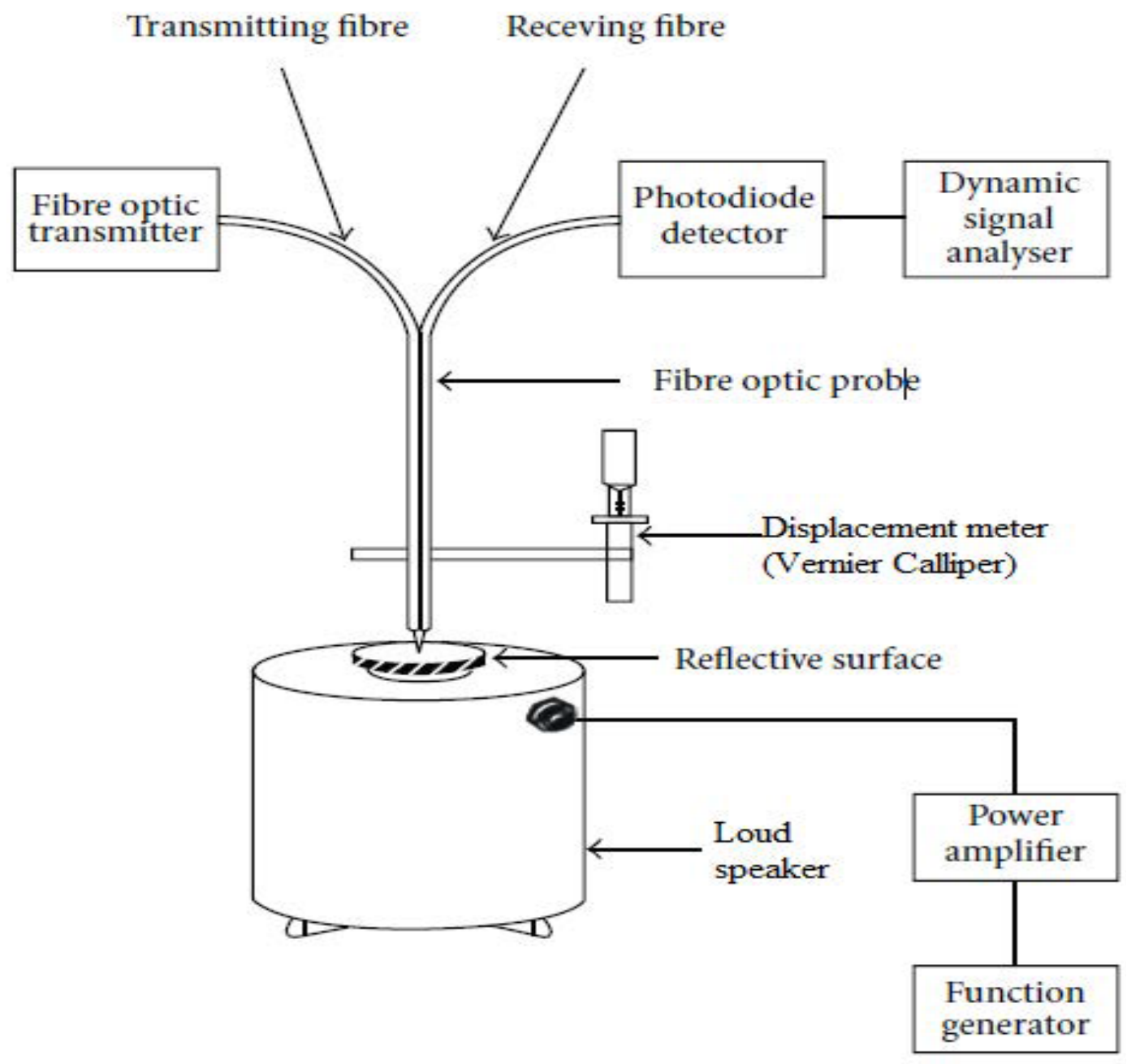

Fig. 1 Schematic of vibration based optic sensor along with experimental setup. 
By using these results, vibrations of a loud speaker were measured. The speaker input was from signal generator and frequency was varied to obtain different levels of vibration of the speaker. The vibration sensor was clamped on to the speaker and one fiber of the bifurcated fiber was connected to an optical power meter, the Led of which formed the light source. The light after reflection from the mirror entered the second fiber which was connected to an optical to electrical converter. The output of the O/E converter was given to CRO where the waveform of the output vibration amplitude and frequency was obtained. The readings of the vibration amplitude and the frequency are given in Fig. 2.

Perrone and Vallan [5] present a new method of measuring vibration signals in which no physical contact of sensors are required with vibrating object. In this noncontact method of measurement cost effective fiber optics is used that is able to provide submicrometer perseverance. Usually, contact sensors, such as strain gauges and piezoelectric accelerometers, are less costly but can only be used for massive vibrating objects to diminish their impact on the measurement. However, in many circumstances of practical interest, the contact sensors cannot be used either because of the trouble of reaching the vibrating

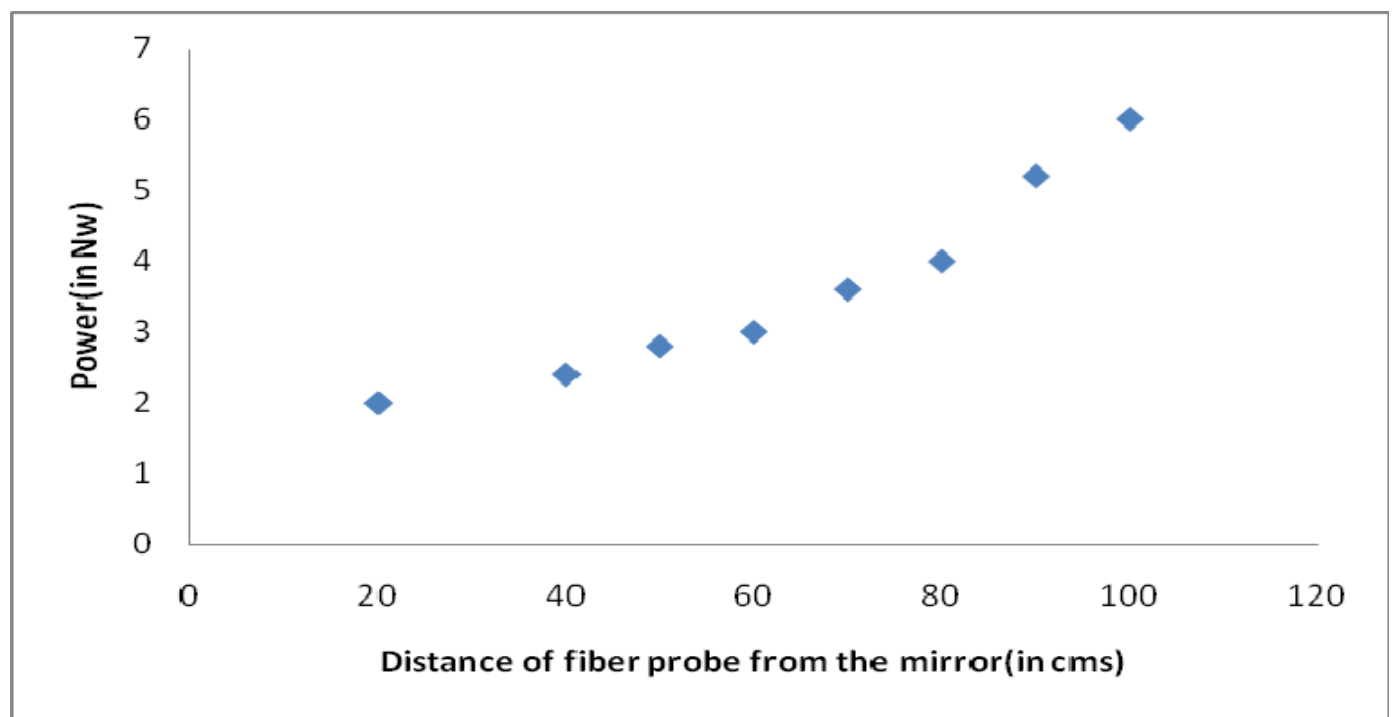

Fig. 2 Results obtained from Vernier caliper and power meter.

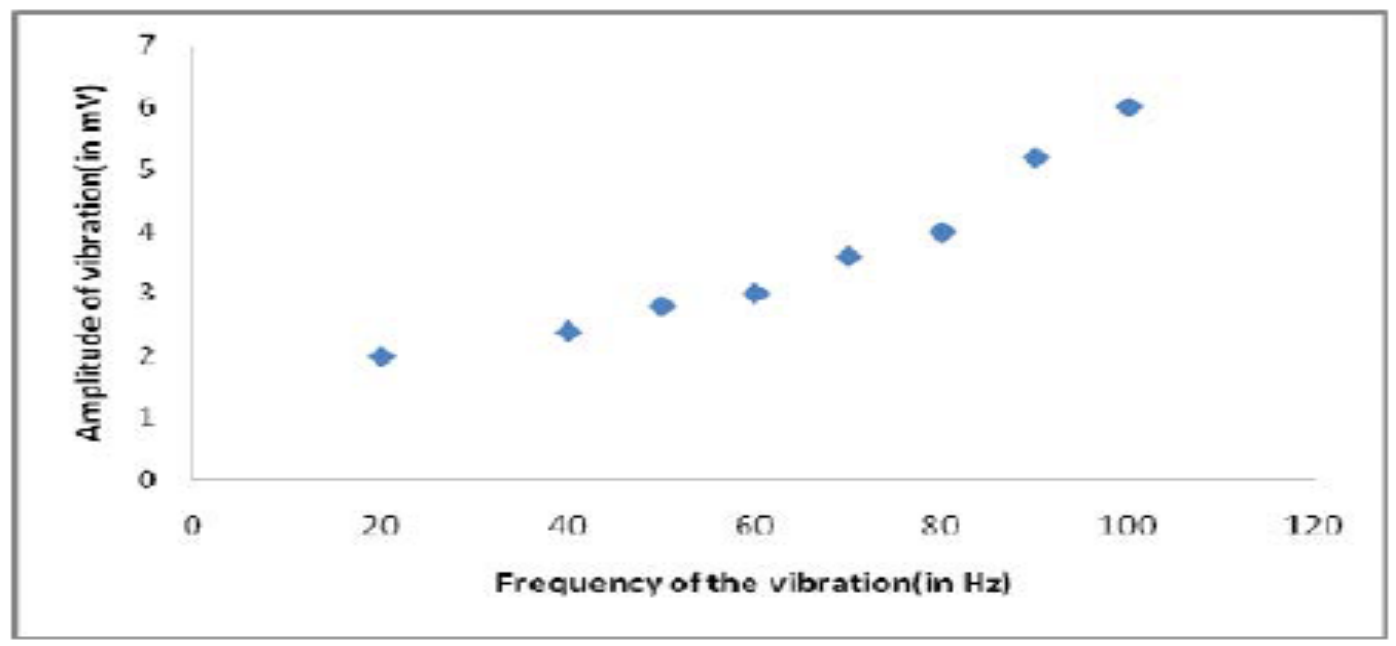

Fig. 3 Results obtained vibration measurement of the diaphragm. 
object or because of its extremely small size. Fiber Optics provides technologies to overcome these limitations, permitting the development of high-performance noncontact sensors, namely the most motivating since they actually do not disturb vibrations. This technique is helpful in case of small vibrating objects and where the contact sensors are difficult to install.

A signal analysis technique based on the HHT (Hilbert-Huang Transform) is deliberated in Ref. [6] for machine health monitoring. The analytical circumstantial of the HHT is introduced, based on a synthetic analytic signal, and its efficiency is experimentally assessed using vibration signals measured on a test bearing as shown in Fig. 4. The consequences validate that HHT is matched for seizing momentary events in dynamic systems such as the transmission of structural faults in a rolling bearing, thus providing a practicable signal processing tool for machine health monitoring.

Bearing misalignment instigated by the inner and outer raceways tumbling out of the same plane caused in periodic vibrations, which can be recognized from its spectrum as presented in Figs. 5a and 5b.

The IMFs of the two data fragments and resultant HHT identified frequency changes at the time instance of $45 \mathrm{~ms}$ during the first data segment and at $55 \mathrm{~ms}$ during the second data segment is shown in Fig. 6.

Such frequency variations reflect squalor of the bearing health condition as the defect broadcasted through the bearing raceway. Substantially, impacts generated by the rolling ball-defect interfaces excite intrinsic modes of the bearing system, giving rise to a train of transient vibrations at the mode-related resonant frequencies. As the defect size rises, different intrinsic modes would be excited, resulting in the change

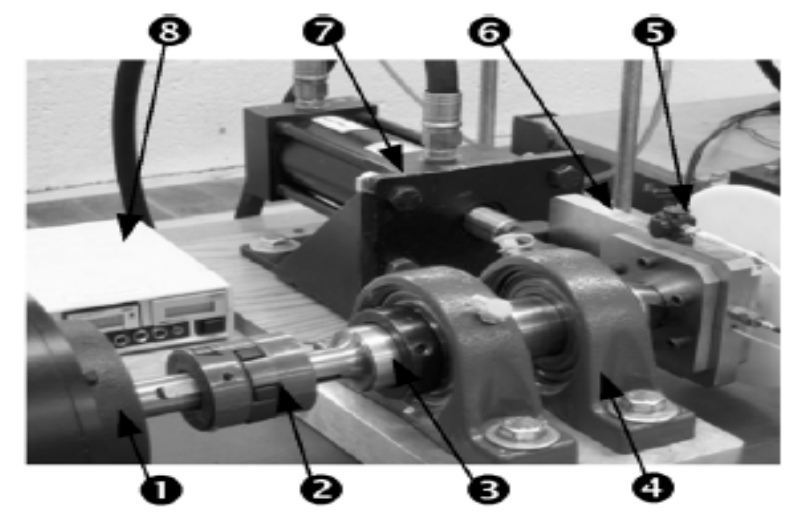
1. DC Motor
3. Shaft
2. Coupling
4. Pillow Blocks
Accelerometer
7. Hydraulic Cylinder
6. Test bearing with Housing
8. Speed Recorder

Fig. 4 (a) Bearing misalignment; (b) Expermental test bed of bearings.
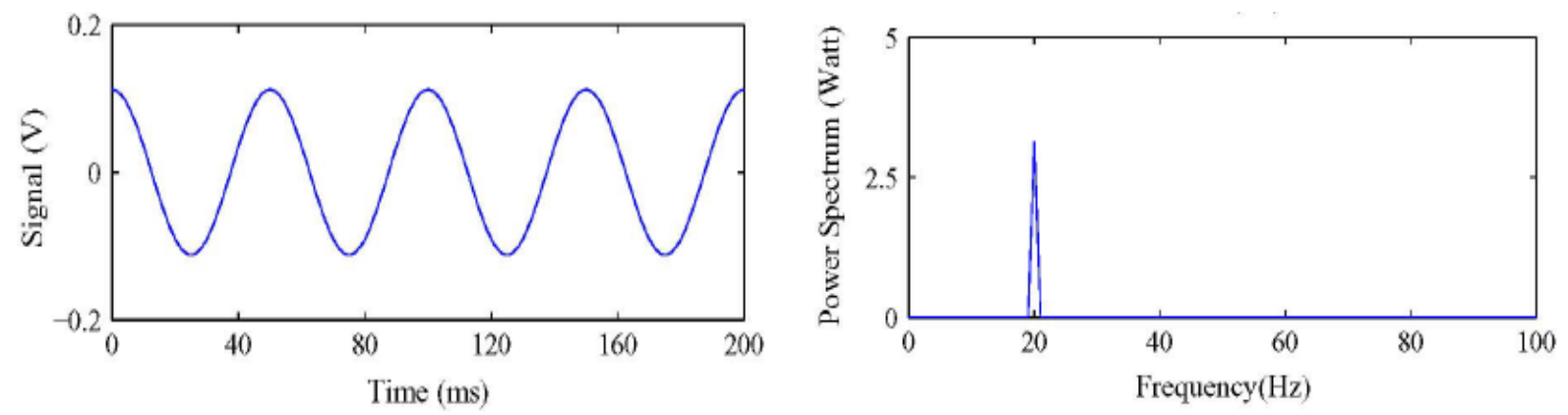

Fig. 5 (a) Periodic vibration by bearing mis alignment; (b) Power spectrum of misalignment. 


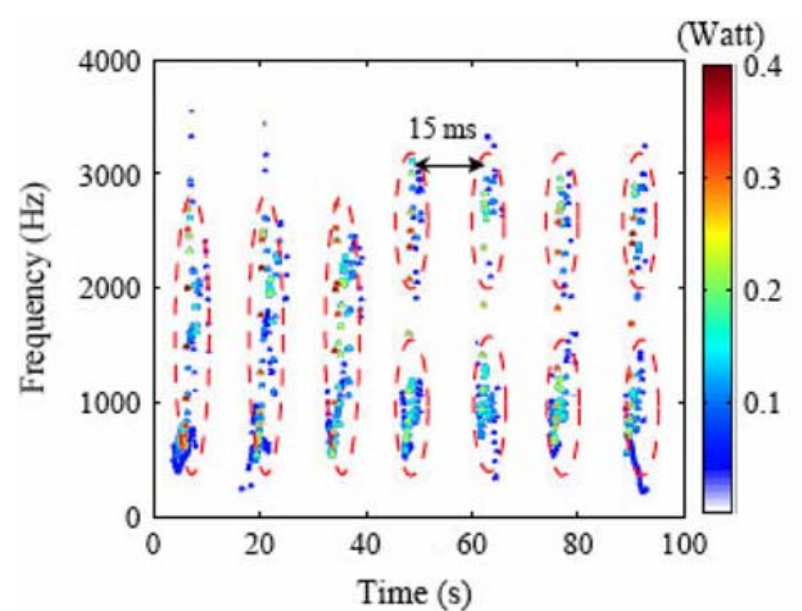

Fig. 6 HHT of the two data parts (part left \& part right).

of frequency components in the transient vibrations. In addition, these transients have shown a monotonous pattern with a $15-\mathrm{ms}$ interval, which relates to a $67-\mathrm{Hz}$ frequency constituent that is associated to a bearing misalignment. Thus, the HHT has shown to provide an operative tool for bearing health diagnosis.

An innovative fault demodulation technique based on TFM (time-frequency manifold) is presented in Ref. [7]. This technique practices the TFM base to demodulate the periodic impulses from rare signals. It essentially comprises two subsequent steps: first, the TFM is attained by addressing manifold knowledge on the TFD (time-frequency distributions); second, a short TFM is implemented as a pattern to do parallel analysis with the original TFD. The projected demodulation method can achieve a high resolution for recognizing stimulating impulse components. The novel method is confirmed to be superior to outmoded enveloping demodulation method by means of simulation signal analysis and application to gearbox fault detection. To approve the efficiency of the proposed TFM-based demodulation method, an application to gearbox fault revealing is offered as follows. The investigational signal was collected from an automobile transmission gearbox. The experimental setup of the gearbox is shown in Fig. 7, with understanding 5 forward speeds and one backward speed in the gearbox. By mounting an accelerometer on the outside casing of the gearbox,

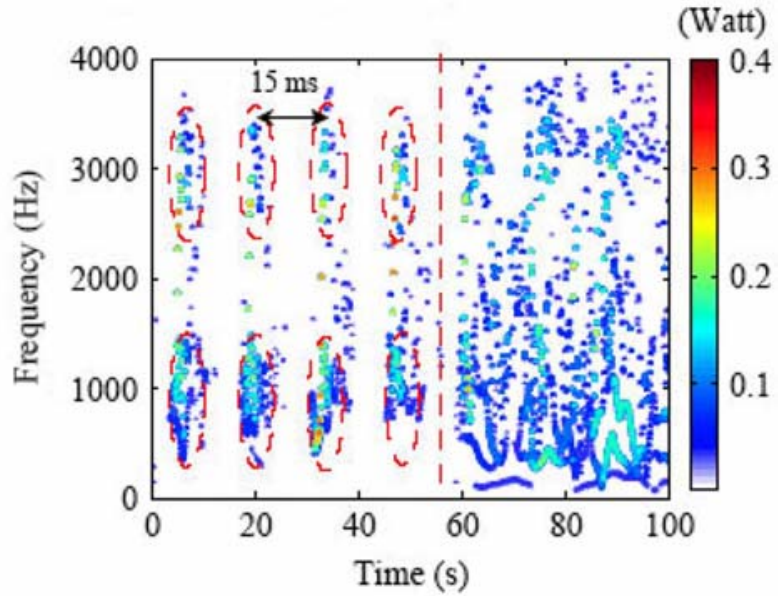

vibration signals are attained when the third speed is loaded. In a fatigue test, a tooth-broken fault happened at the driving gear of the third speed at the beginning of Cycle 7. Thus Cycle 6 corresponds to the severe wearing fault juncture. During the experimentation, the input rotating speed was 1,600 rpm and the sampling frequency was set at $3,000 \mathrm{~Hz}$. The rotating frequency of the tested gear and the meshing frequency are measured to be $20 \mathrm{~Hz}$ and $500 \mathrm{~Hz}$, respectively. As realized from Fig. 8a, the fault signature cannot be recognized directly from the time domain. Fig. 8b designates the spectrum of the faulty signal. It can be realized that there is not the modulation singularity at the meshing frequency of $500 \mathrm{~Hz}$. Though, there is an understandable characteristic band at around $280 \mathrm{~Hz}$, which designates another kind of modulation: resonance frequency modulation. As shown in Fig. 8c, the spectrogram offers an amalgamation of time and frequency information, which can state how the amplitude occurs with the time and the frequency in the modulation.

A model for assessing the sternness of bearing faults as well as experimental techniques is illustrated in Ref. [8] that can be used for lingering bearing life approximation by processing the vibration signal. The projected technique used in this model inspects the spectral content of vibration signals transversely frequency bins and then fits Gaussian deliveries to each 


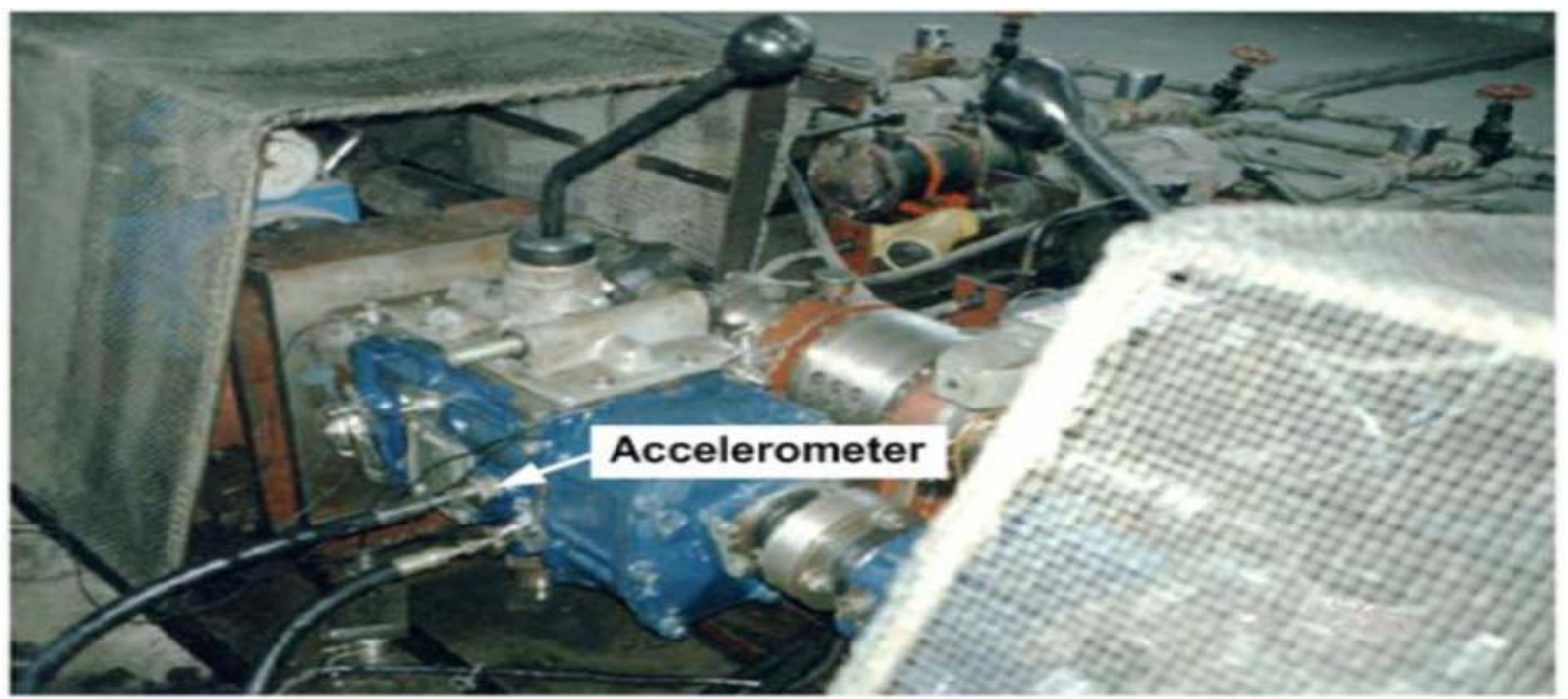

Fig. 7 Experimental set up for monitoring of the gear box of an automobile.
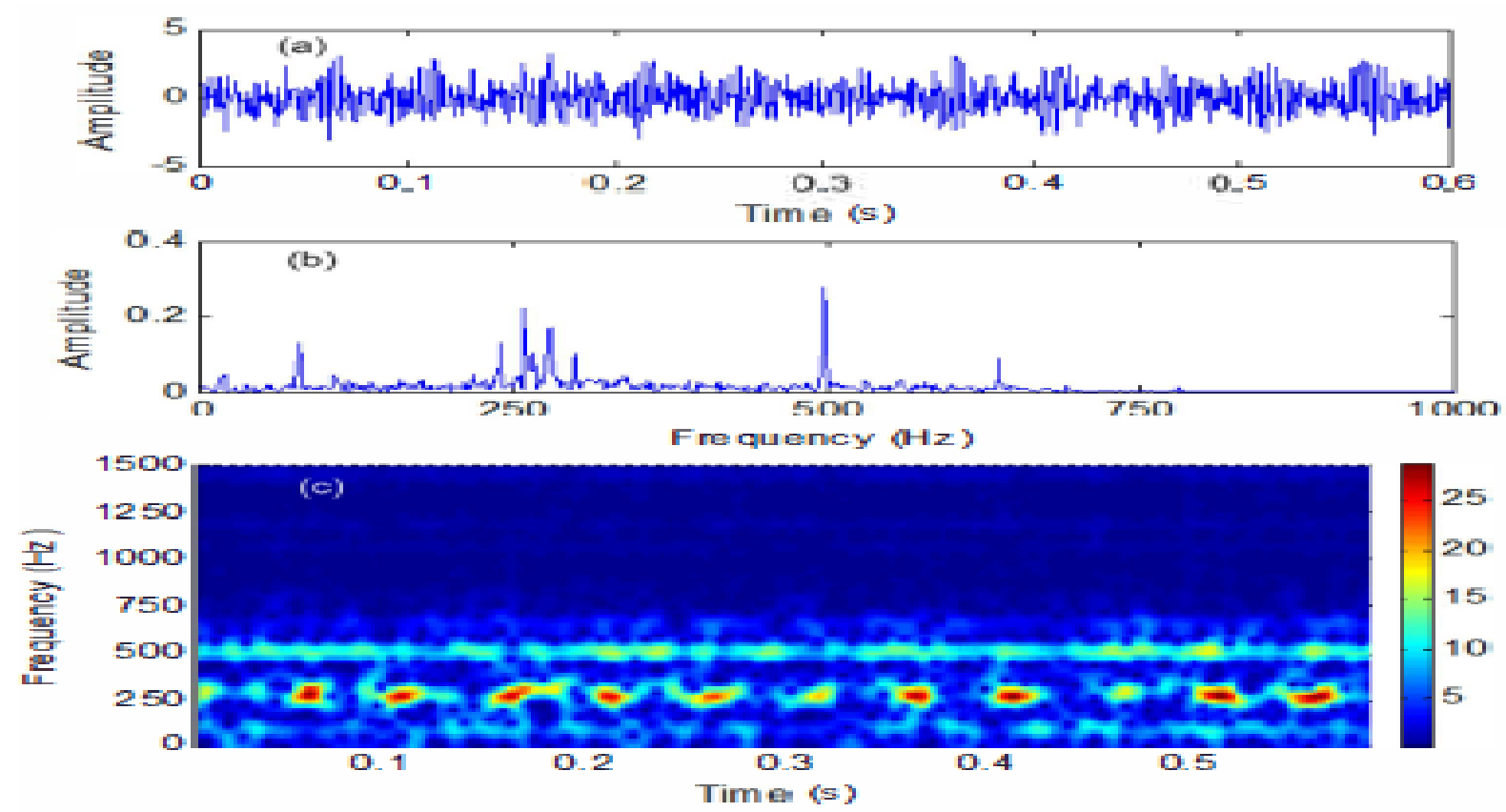

Fig. 8 (a) Faulty signal in view form; (b) Spectrum of faulty signal; (c) Spectrogram of faulty signal.

frequency bin. With the use of these Gaussian models and exercise set examples with dissimilar fault severity levels, characteristic involvement functions are constructed. This permits approximation of the severity levels of the bearing faults through a fuzzy-logic enthused process, whereby the severity level resembles to the maximum of the set of corresponding membership functions. Thus based on discrete fault severity levels, trained Gaussian fittings of spectral bins and characteristic fault membership functions are proficient to guesstimate the fault severity on a continuous scale. Fig. 9 illustrates the experimental setup for recording the authentic vibration data sets for the bearing inner-race fault intensity approximation as a submission of the proposed algorithm. The test stand contains $2 \mathrm{HP}$ motor, a torque transducer/encoder, a dynamometer.

The consideration bearings edibles the motor shaft electro-discharge machining was used to introduce single point inner-race fault of $0.007,0.014,0.021$ and 
0.028 inches. Vibration signal from encouraged faults was apprehended with accelerometers and data were recorded in digital format at 12,000 samples per second using a 16 channel DAT recorder.

After the fault inception as the fault severity increases the spectral contents of the fault shift from one particular position towards second. According to the proposed algorithm as the fault severity keeps growing, the membership of one characteristic fault membership function decreases and second one's increases. The situation is vivid in Fig. 10.

A non-contact SHM (structural health monitoring) system for machine tools based on the vibration signal is demonstrated in Ref. [9]. The vibration signal is collected through a low-cost, microcontroller based data acquisition system. The inspection tests of this established system have been carried out on a vibration rig as shown in Fig. 11. The readings have also been calibrated with the accelerometer to authenticate the projected system. The established system results in swift measurement, allows consistent monitoring, and is cost operative with no requirement to modify the structure of the machine tool.

Fig. 12 shows the comparison of disparity in vibration amplitude measured by both contact and non-contact type instruments in the $X$-axis to monitor

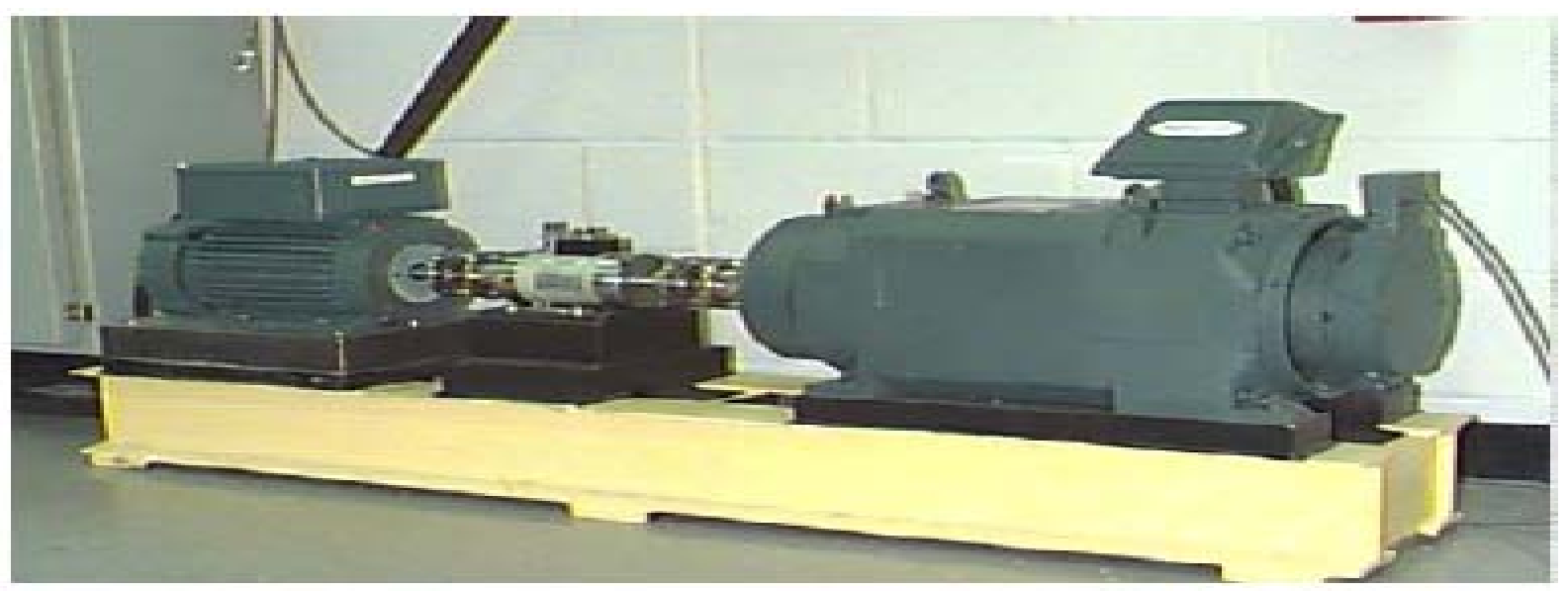

Fig. 9 Experimental setup for the bearing fault detection.

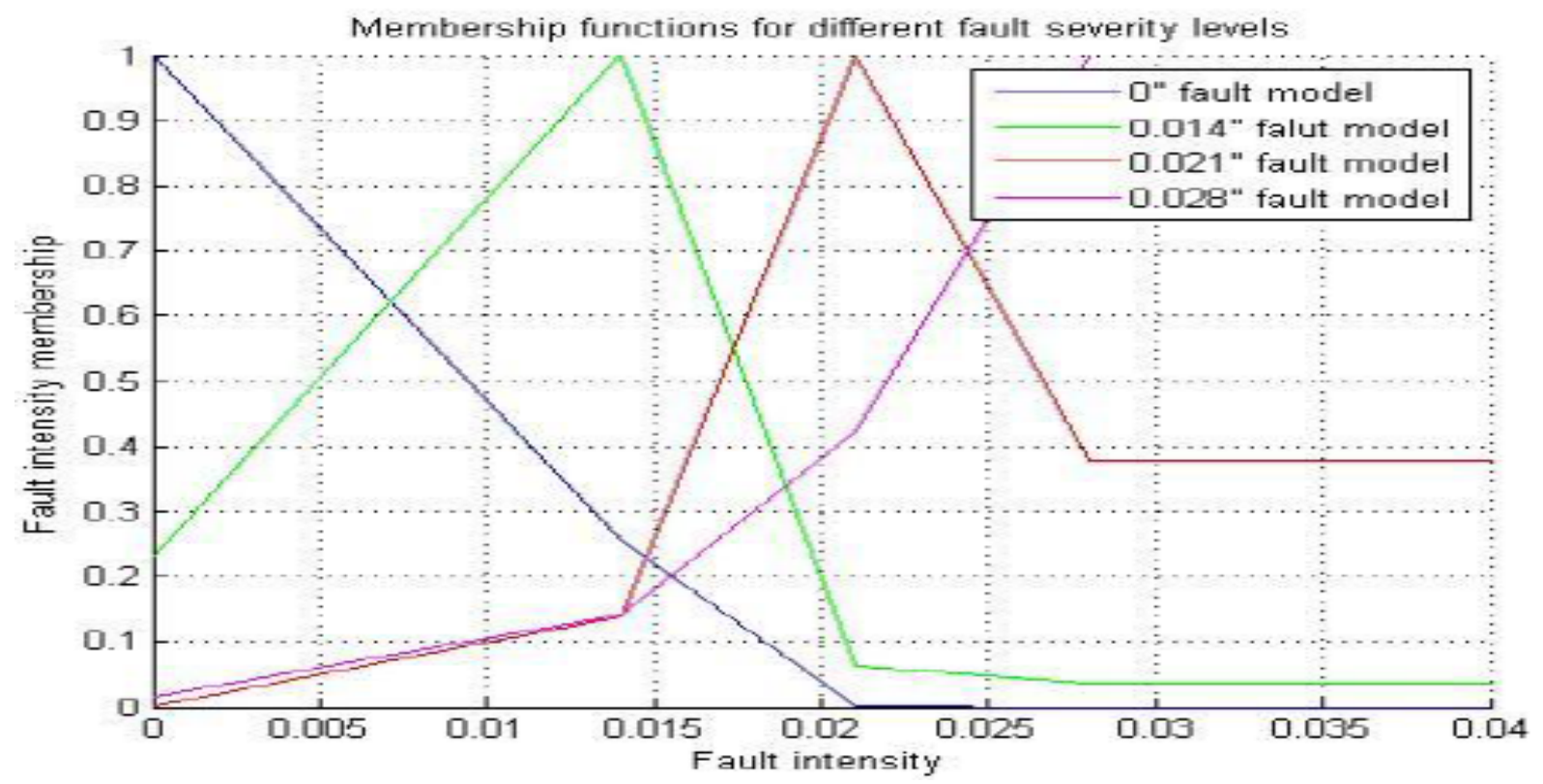

Fig. 10 Four point fault characteristic membership function. 

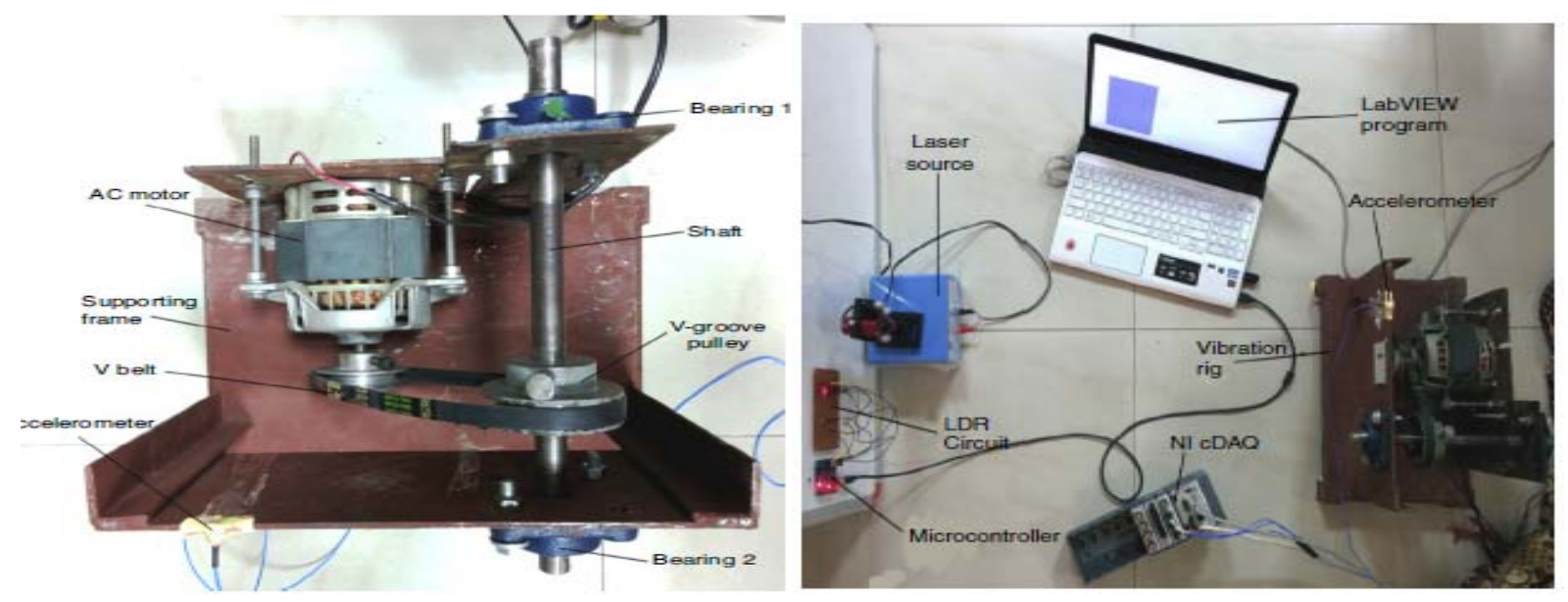

Fig. 11 (a) Vibration test rig; (b) Experimental setup of non-contact structural health monitoring systems.

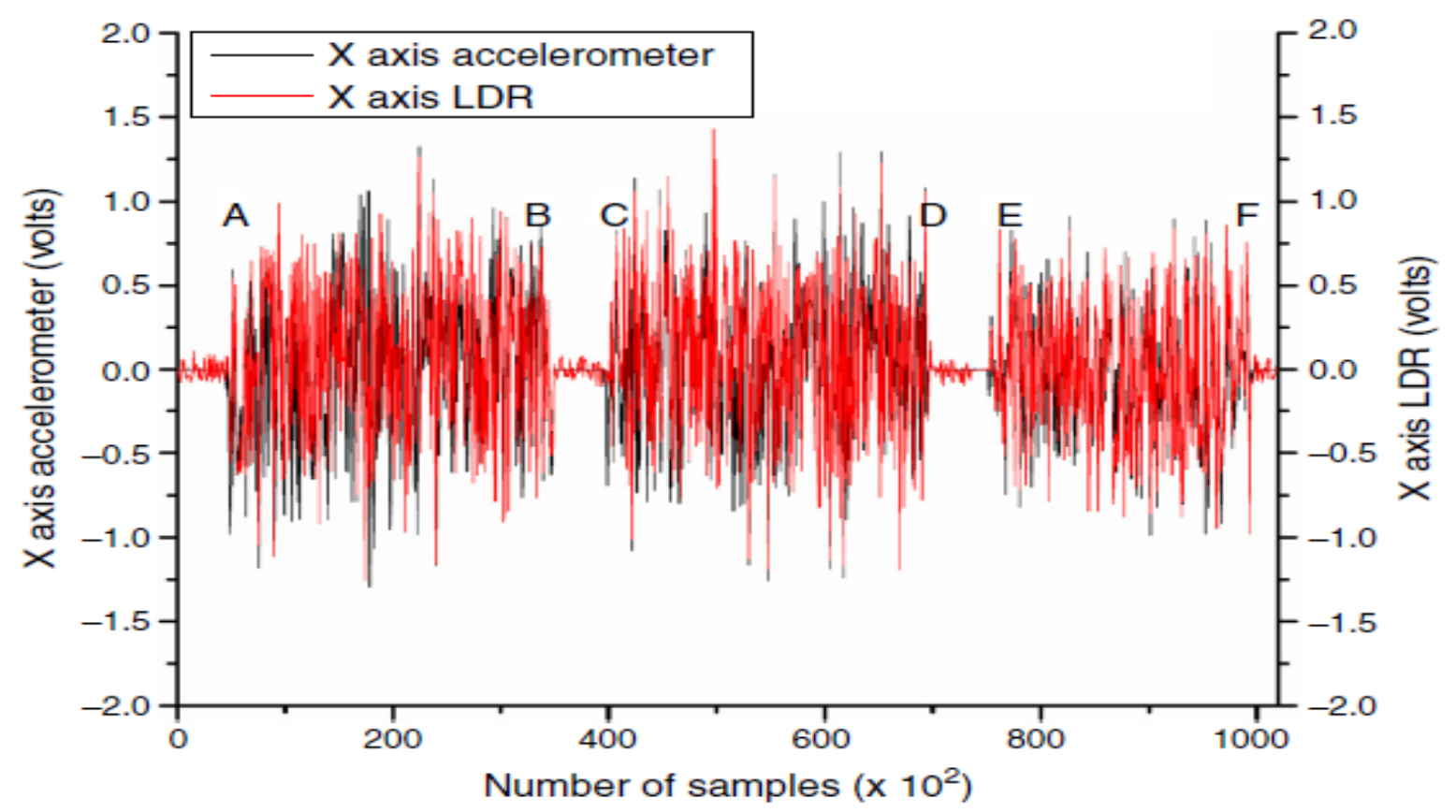

Fig. 12 Comparison of vibration signature for the LDR and theaccelerometer vs. no of samples [0-100 k] in $X$-axis.

the health of the machine. It has been detected that the advanced system gives almost the same values like the contact type device.

An experimental test to inspect the vibration features in two dissimilar kinds of cracks in an extensive rotor shaft is described in Ref. [10]. The methodology used here is to set up experimental apparatus (see Fig. 13a), progress a vibration detection system, and make best use of the dynamic range. Fatigue crack instigation and promulgation in a pre-cracked high carbon steel shaft was experimentally estimated and examined using a vibration based condition health monitoring method.

The credentials of the alteration amongst three diverse pre-crack depths and five different runs after the crack's growth display shifts in the frequency spectrum and alterations to the peaks' amplitudes. The consequences of the tests and analysis evidently validate the possibility of using vibration to notice the change in frequency of a shaft due to a change in stiffness such as those related to a shaft crack. In conclusion, examination was carried out on the fracture surface in order to express the fatigue crack depth inside the shaft. The results indicate the fatigue 

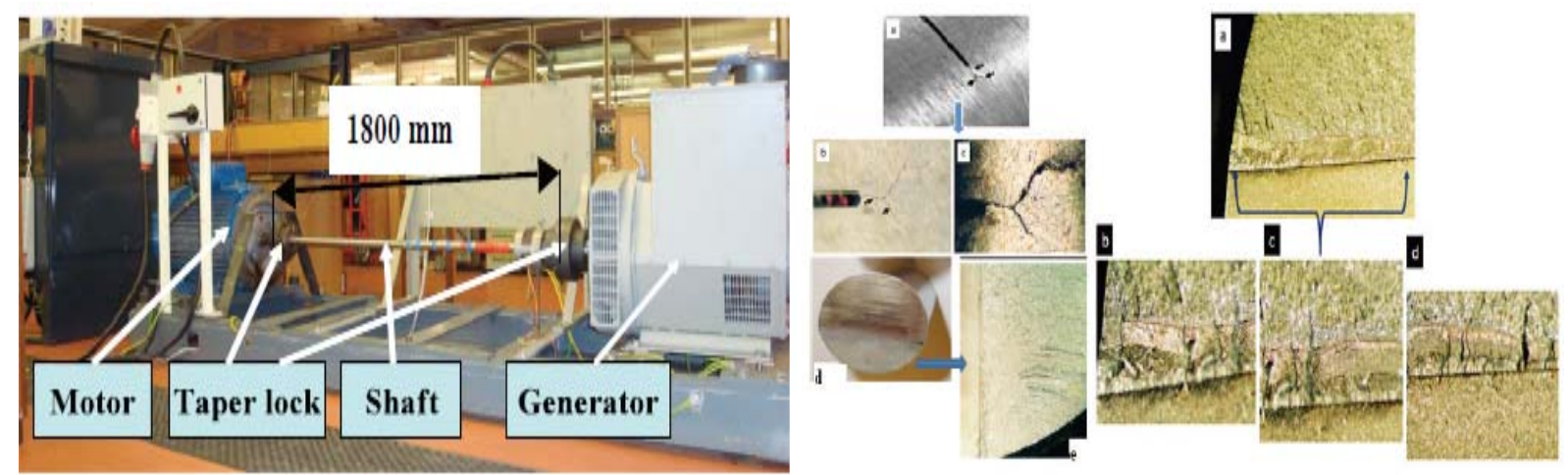

Fig. 13 (a) Shaft tig; (b) Crack on shaft body and crack internal propegation stage.

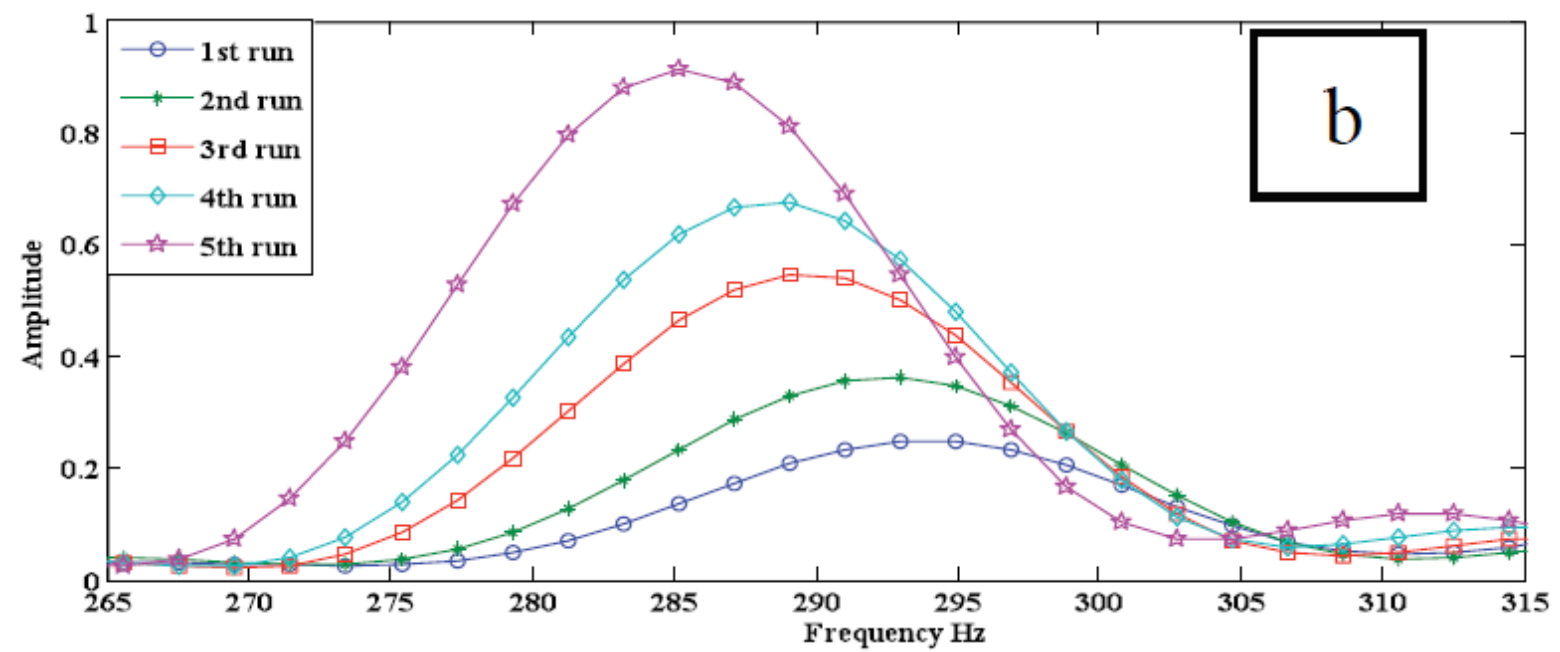

Fig. 14 Vibration spectra for various cracks frequency ranges $(265-315 \mathrm{~Hz})$.

crack fracture surface along the notch depth. A segment of the crack surface is accessible in close up viewing the fatigue crack beach marks, and indication that the fatigue proliferated along the artificial notch internal boundaries.

The growth of crack in a shaft is identified with various frequency ranges. However, the frequencies ranges $265-315 \mathrm{~Hz}$ and $266-315 \mathrm{~Hz}$, demonstrate a very virtuous result (see Fig. 14) for perceiving the crack growth by a clear growth in the amplitude and by the frequency shifting to the left (a frequency reduction occurs).

Dynamic machining performance is investigated in Ref. [11]. A lead screw of 718 CNC machine as test part is used. Design the test scheme and positions of sensors reasonably. For design algorithm and data processing, there is a disturbance in the vibration signal gained from sensors so it is essential to clear up disturbance of vibration signals. To some key parts, such as lead screw, proceed the low-frequency and high-frequency signals from vibration signals. In order to upsurge processing speed of assessing machining performance, decrease the number of data in the case that the system can encounter necessities of precision. And clustering method is used to route vibration signals. That is segmenting vibration signals into some minor parts. Calculating the mean of data in each small part to be the data of this part. For the lead screw of 718 CNC, the number of data is 65,536 . Though, when set threshold to be $0.005 \mathrm{~V}$, the number will decrease to be 16,381 when processing the data with clustering. Hence calculating time will be decreased a quarter. Approximating the performance of lead screw to 718 CNC with dynamic BP network, 
as well as classifying the results into two parts (normal state and faulty state) was carried out. The dynamic machining performance is accurate in the circumstance of normal state and the dynamic machining performance cannot encounter the machining accuracy obligation. The results of simulation show that the method can correctly classify normal state and faulty state.

Wireless vibration monitoring as early fault detection is investigated [12, 13]. In collaboration with Oslo Water and Sewerage works a medium-sized water pumping station was designated as the location for the pilot setting up as shown in Fig. 15. The pumping station comprises four parallel water pumps positioned in the basement of the facility. During usual conditions only one or two of the pumps are in operation. Four electric motors, one for each pump, are placed on the ground floor.

In order to monitor the condition of the rotating machinery at the selected site, the motors and pumps were fortified with wireless vibration sensors. The sensors, three for each motor and one for each pump, were of the type WiMon 100 from ABB. The sensors interconnect wirelessly by using the Wireless HART standard, allowing fitting and battery-supported operation deprived of the use of wires. A Wireless HART entryway from Pepperl+Fuchs was positioned in the ground floor of the facility, permitting wireless communication with all the WiMon 100 sensors. The Wireless HART gateway also had a wired Ethernet connection to an on-site laptop running the WiMon Data Manager for network configuration, data acquisition and data analysis. The on-site laptop was remote-controlled by $A B B$ in excess of the Internet.

The system architecture is illustrated in Fig. 16. This figure also indicates how the sensors linked to motor 4 and pump 4 interconnect with the gateway. As stated earlier that Wireless HART delivers multi-hop communication when direct links do not offer adequate excellence. Such a multi-hop route can be detected at the sensor on pump 4, which practices one of the sensors on motor 4 as a relay for conveying data to the gateway. This direction-finding is handled automatically by the gateway all over the entire lifetime of the network, and is dynamically rationalized according to provisional or perpetual link quality variations due to noise, interference and/or fading. Similar routing paths are working by the sensors on motors and pumps 1-3, although not demonstrated in the figure.

A specimen of the results is presented in Fig. 17, where the frequency spectrum of the vibration measurements from motor 2 is exposed. Here, there are clear monotonous energy prickles at 3.09× RPM.

A SVMS (smart vibration monitoring system) is

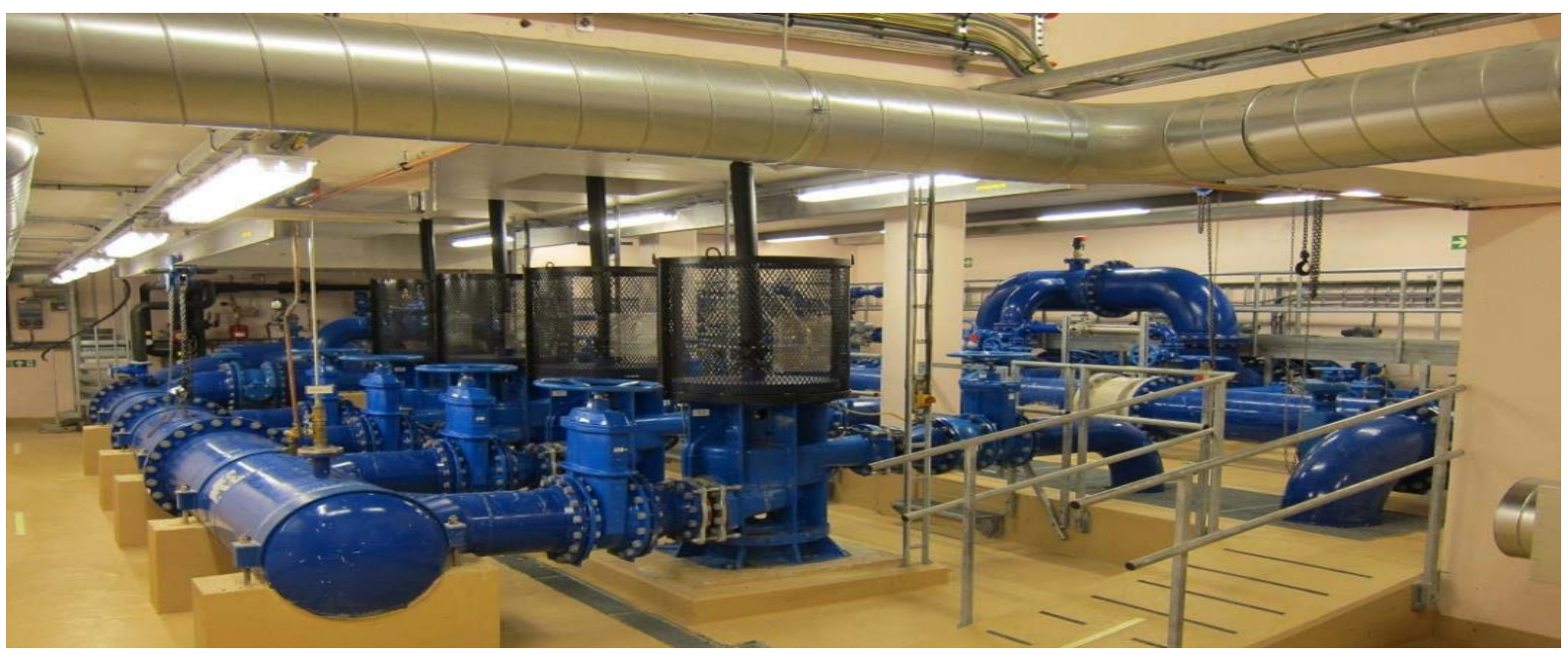

Fig. 15 Oslo water pumping station (Norway). 


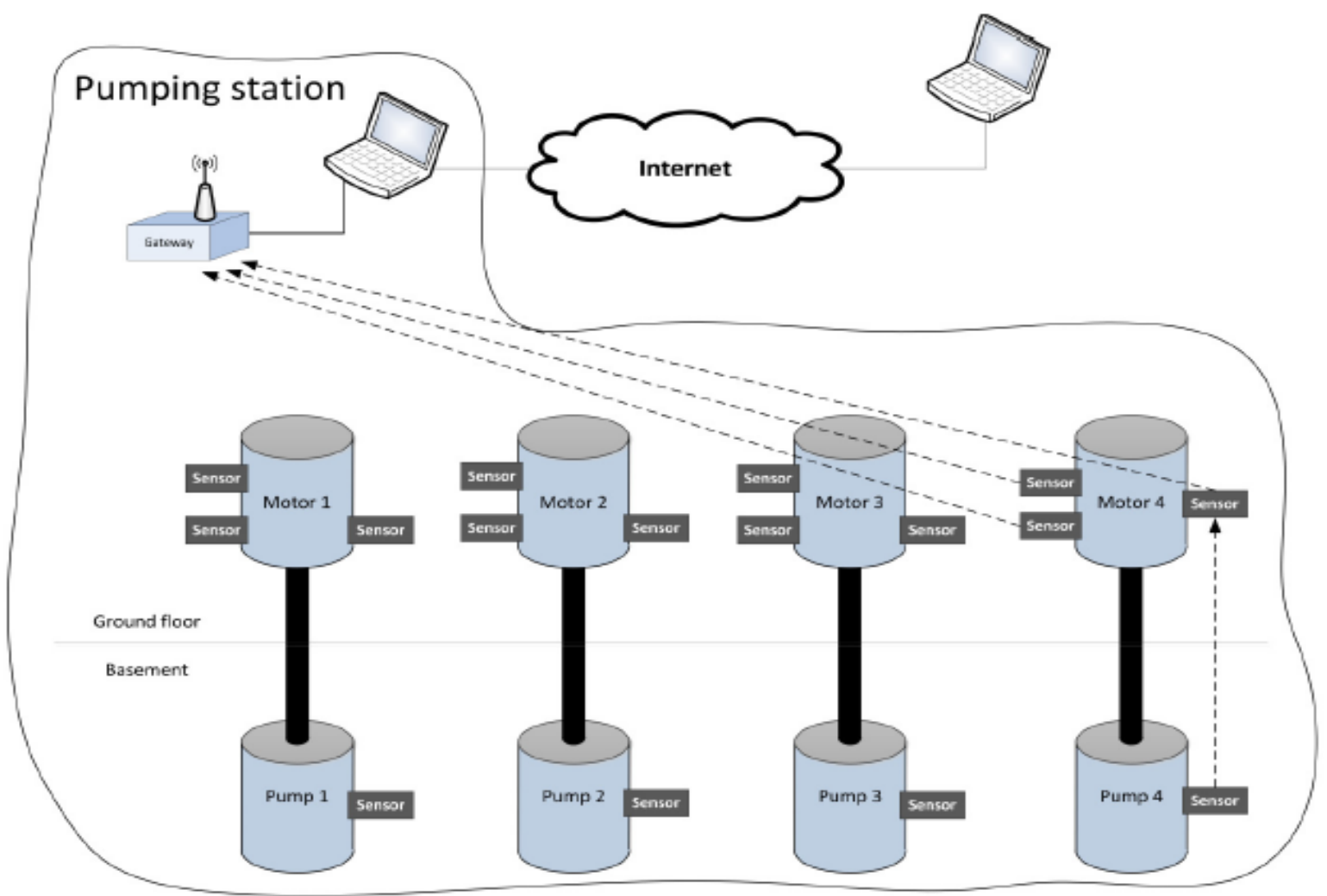

Fig. 16 Architicture of the communication link from the sensors.

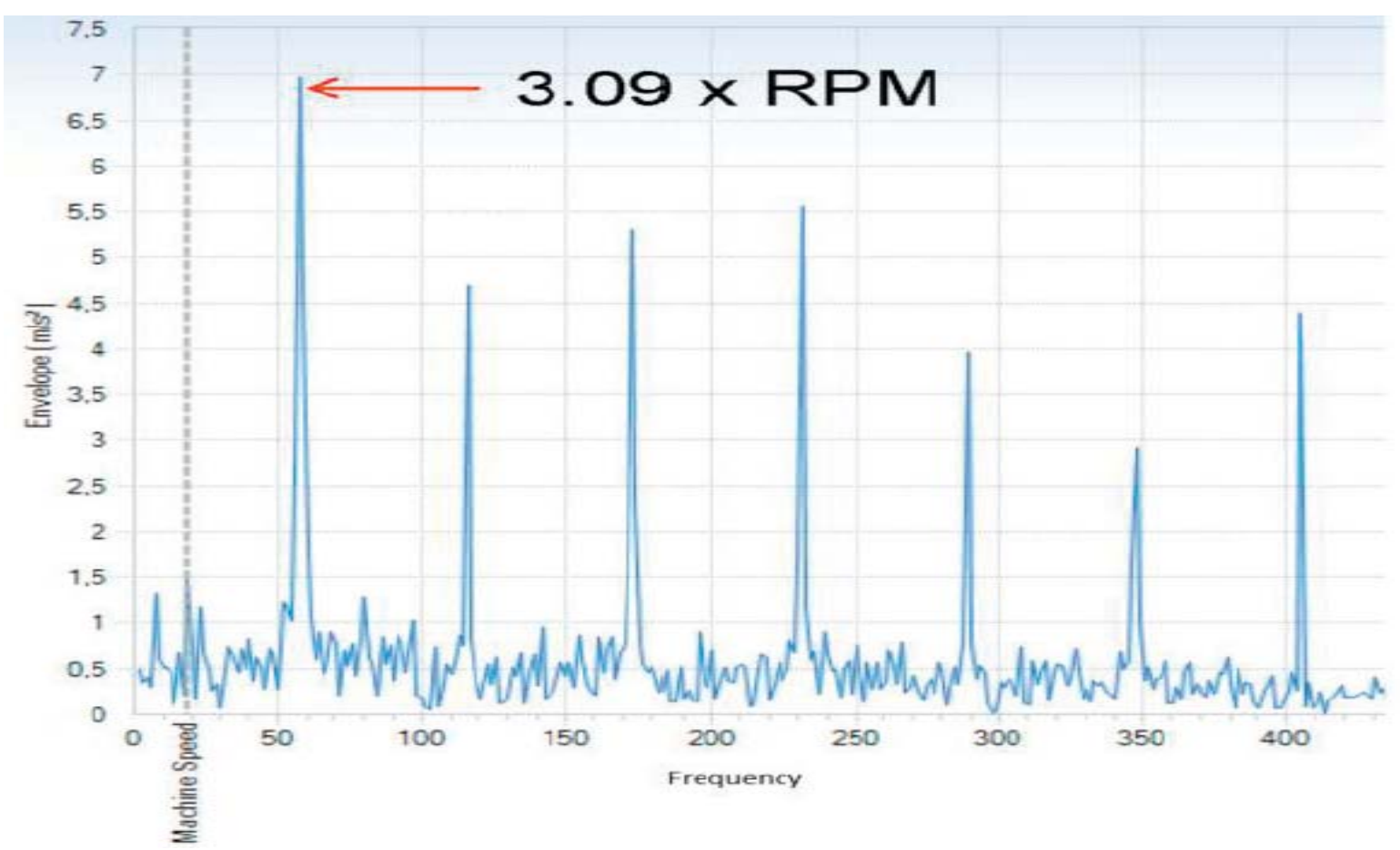

Fig. 17 Vibration analysis for motor 2.

developed in Ref. [14] as an active way to decrease equipment fatalities and improve safety, effectiveness, consistency, availability and long life time period of an ocean turbine. The system develops progressive signal processing and analysis practices to assess the health of a machine and recognize emerging 
irregularities (faults) and evaluate their harshness relative to the machine's condition. The SVMS was tested on a dynamometer (Fig. 18) running at different speeds with simulated faults to evaluate the ability of the algorithm to diagnose faults. The dynamometer represents the electrical and mechanical equipment of the actual OT. The drive motor simulates the load applied by the propeller on the shaft, as the ocean current causes the propeller to rotate. Injecting simulated faults in the coupled dynamometers while avoiding damage to the machine was quite difficult to implement in practice, therefore the motor drive and the two stage planetary gearbox (simulated rotor) section of the dynamometer (Fig. 18) were detached and instrumented.

The trials were accomplished on the rotor section of the dynamometer working at two different shaft rotational speeds (52.47 RPM and 73.07 RPM). Note that these revolving speeds agree to 1,144 and 1,593 RPM for the "ocean current" electric motor, due to the occurrence of a gearbox. In accumulation, the tests were accomplished for three different level sternness of the shaft imbalance fault: (1) with a light weight (2 magnets of $0.5 \mathrm{lbs}$ ); (2) with a medium weight (2 blocks of $2.375 \mathrm{lbs}$ ); and (3) with a heavy weight (2 magnets and 2 blocks, 2.875 lbs total; Fig. 5) attached to the end of the output shaft. The distance from the shaft axis to the site of the weights was 3.7 inches. Changes in third octave bands, power spectral density, cepstrum, Hilbert envelope, RMS level were automatically identified and imbalance fault was precisely identified in real time. The acceleration data were collected using a Low Frequency [0.2-3,000 Hz] piezoelectric accelerometer with a sensitivity of 500 $\mathrm{mv} / \mathrm{g}$ mounted on the torque meter. The sampling frequency was 5,000 Hz. 20,000 data points were collected in each sample. The frequency resolution was $0.25 \mathrm{~Hz}$. A total of 500,000 points were acquired (25 samples). A Henning window was used to smooth the data.

The investigational results accessible in this section resemble to the dynamometer running at 1.144 RPM. Fig. 19 shows the phase where the SVMS opens up the PSD in the identified $63 \mathrm{~Hz}$ third-octave band (56.12 to $70.71 \mathrm{~Hz}$ ) and zooms on the functioning frequencies (59.5 and $61.5 \mathrm{~Hz}$ ) that instigated this band

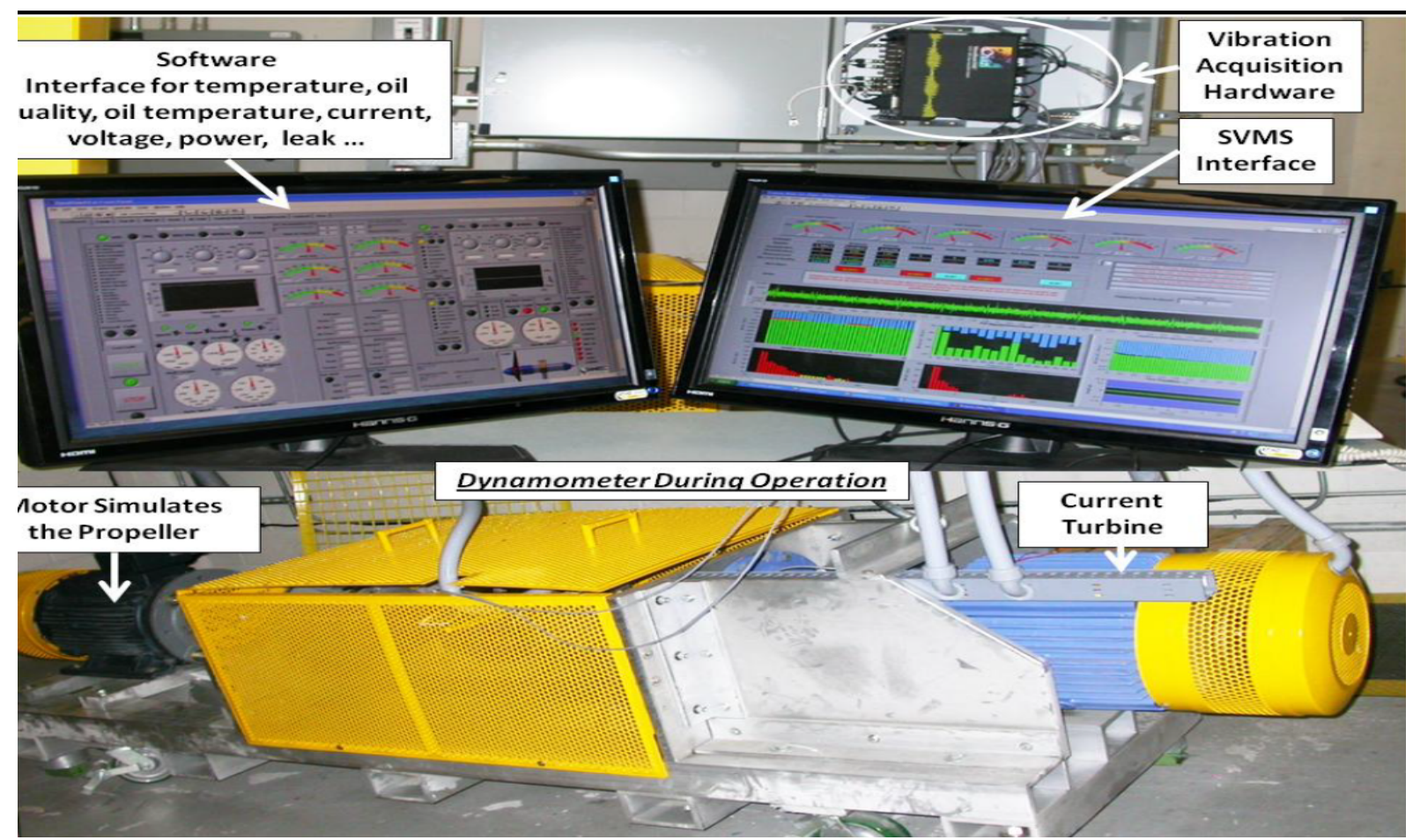

Fig. 18 The experimental setup for SVMS and dynamometer control units. 


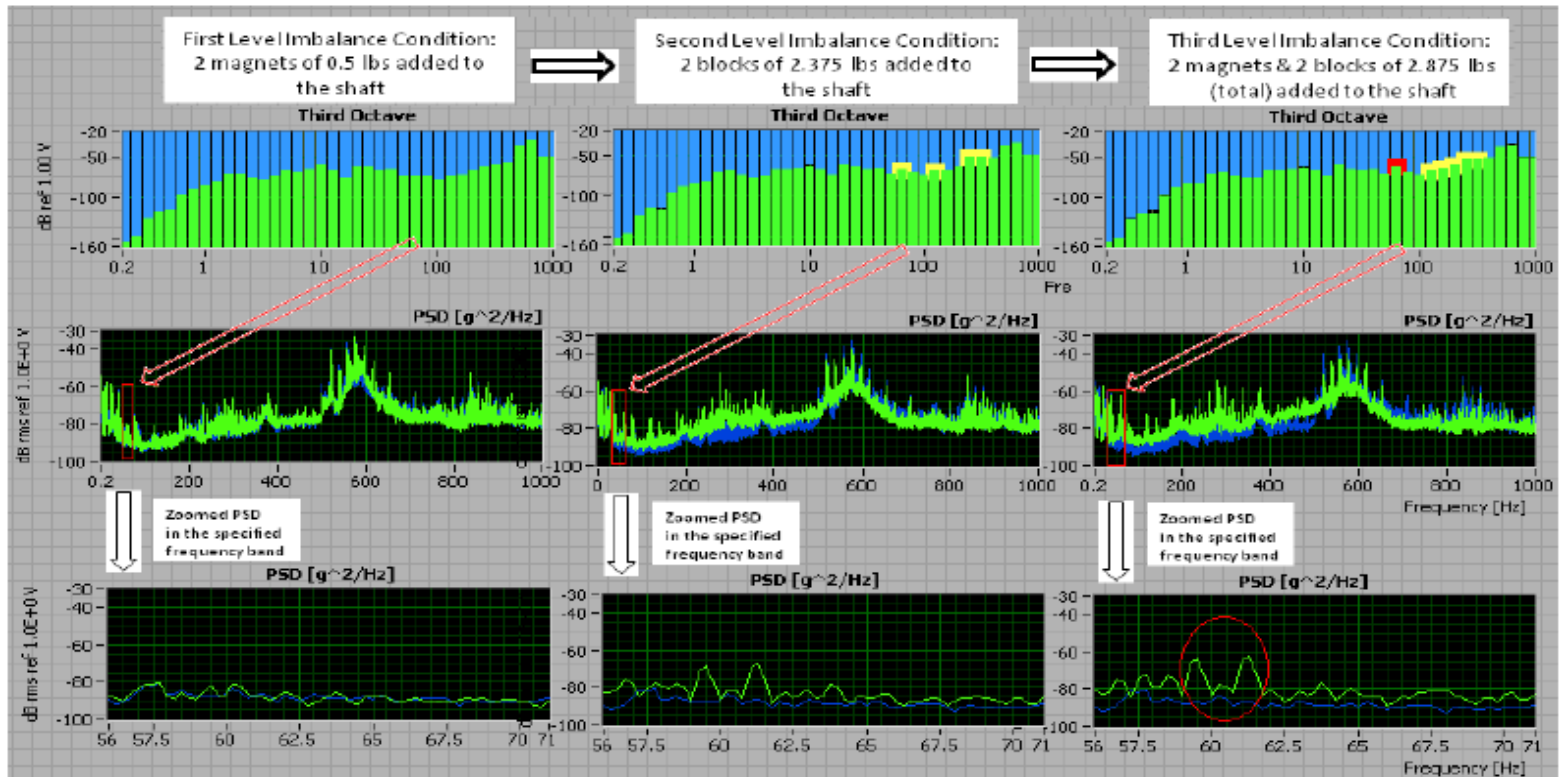

Fig. 19 Frequency identification components (automatic PSD zoom in the failed third octave band).

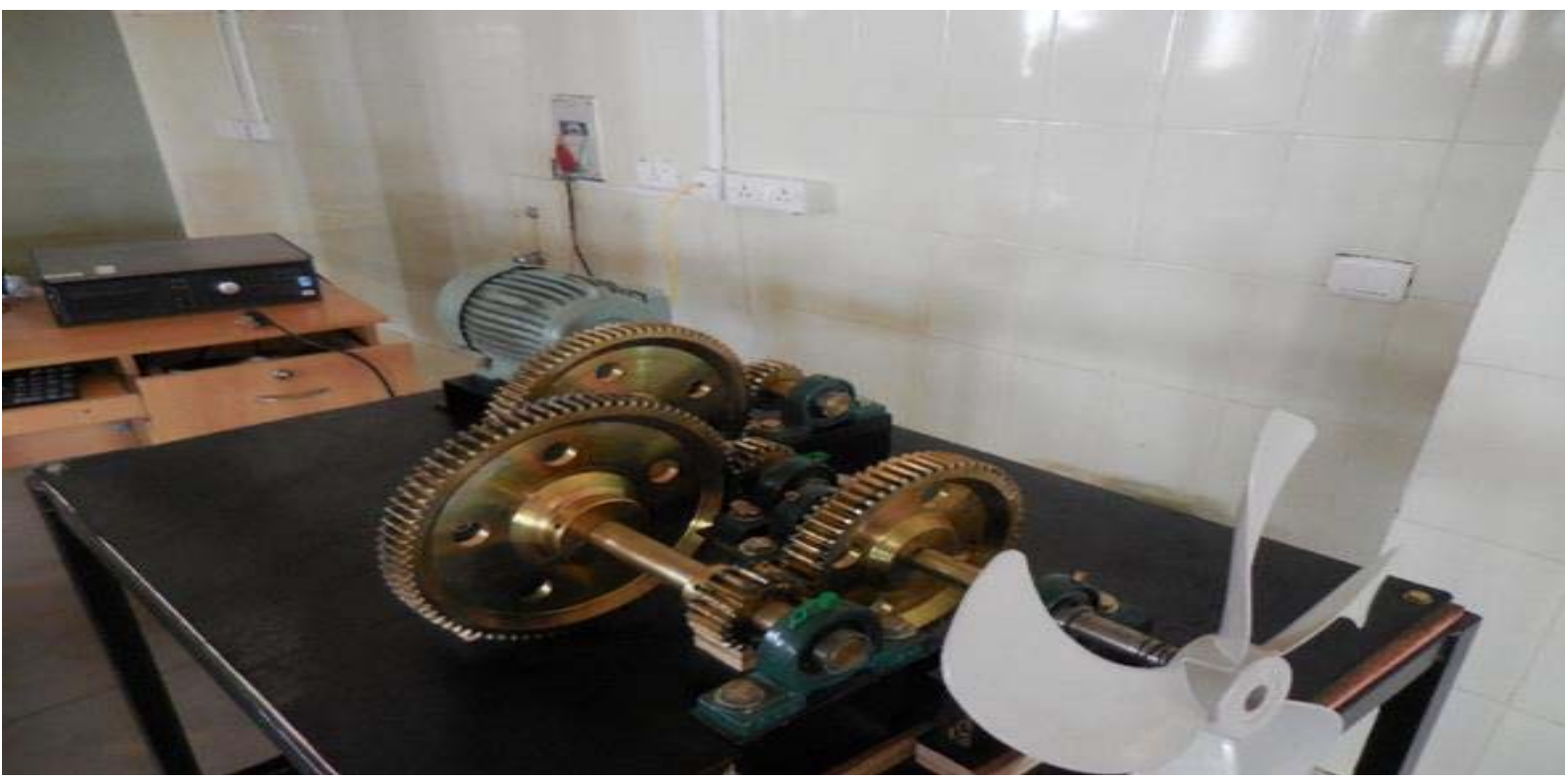

Fig. 20 A test rig for wind turbine.

to exceed its baseline. Certainly, the augmented imbalance of the shaft caused by the weight ensued in amplitude upsurge of the $59.5 \mathrm{~Hz}$ (gear mesh frequency) and $60.5 \mathrm{~Hz}$ (sum of the gear mesh frequency and the shaft speed). The $61.5 \mathrm{~Hz}$ peak was produced due to the modulation of the gear mesh frequency $(59.5 \mathrm{~Hz})$ and its harmonics with the shaft speed $(1 \mathrm{~Hz})$.

A wind turbine test rig is demonstrated in Ref. [17] at BITS-Pilani, Hyderabad Campus to simulate the operation of a wind turbine. Time domain vibration signals are assimilated using accelerometers for the healthy as well as faulty components. Discrete wavelet transform of vibration signature is accomplished and features are extracted from the statistical analysis of wavelet coefficients and the pull out features are used as inputs in an ANN (artificial neural network) to successfully envisage the size of gear root crack.

A wind turbine test rig was developed at BITS-Pilani Hyderabad Campus to perform condition 

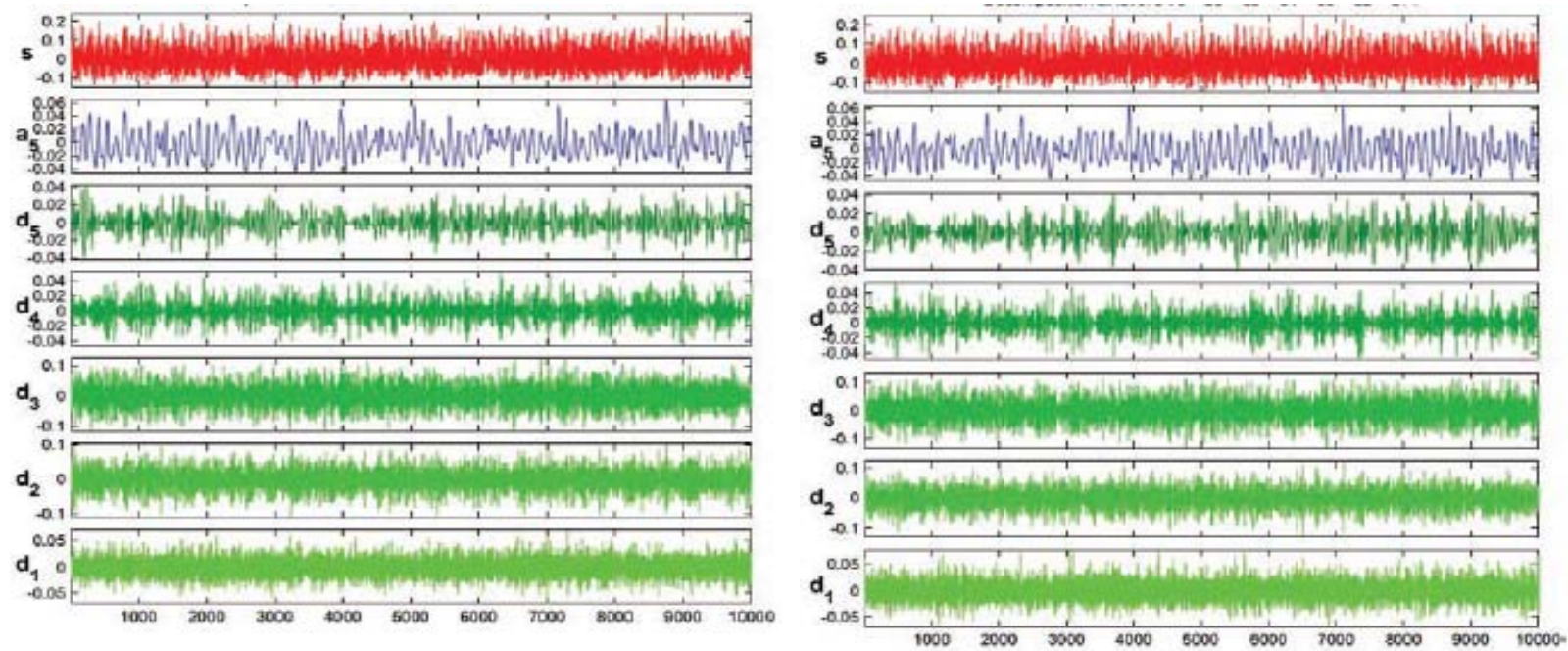

Fig. 21 Signal breakdown for faulty gear with $1.5 \mathrm{~mm}$ and $2.5 \mathrm{~mm}$ depth crack.

monitoring studies as shown in Fig. 20. The wind turbine test rig comprises of three stage gear train having an overall speed ratio of 48:1. A 1hp (horse power), 3phase AC motor was used in place of generator to perform the experiment and the speed of the motor was controlled by variable frequency drive. Three test cases including one for healthy condition and other two cases for faulty condition were performed. In order to simulate the faulty condition, two different root cracks were introduced to the gear tooth individually.

The research was conducted at 1,200 rpm and the vibration signatures were collected using a manufacturing accelerometer and National Instrument Data Acquisition System (NI DAQ 9234) consuming 10,000 sample length and with a sampling rate of $2,400 \mathrm{~Hz}$. The pinion was abstaining 20 teeth with module 3, 200 pressure angle and involute profile. The GMF (gear meshing frequency) was premeditated to be $400 \mathrm{~Hz}$ using GMF= $\left(\mathrm{t}^{*} \mathrm{rpm}\right) / 60$ where " $\mathrm{t}$ " is number of gear teeth and "rpm" states the speed of pinion. For each test case, 80 numbers of discrete time domain signal samples were kept together and these time domain vibration signals were auxiliary analyzed to envisage the fault size in the gear of wind turbine test rig. The fault size was foreseen by means of a feed forward back propagating ANN with five hidden layers. Gradient descent with momentum algorithm was used to sequence the network.

The geographies gained from wavelet transform of time domain vibration signal were used as input to the ANN and the gear tooth root crack depth was prophesied with $88.2 \%$ and $90.08 \%$ accuracy for 1.5 $\mathrm{mm}$ depth and $2.5 \mathrm{~mm}$ respectively as shown in Fig. 21. The results achieved will be helpful for gaining the severity of fault as well as residual useful life prediction.

\section{Conclusions}

A comprehensive study of the vibration monitoring of electrical rotating machines reveals the ionic fact that Predictive maintenance is a very useful exercise in a manufacturing plant. The machine vibration signals both in healthy and faulty conditions of various rotating systems were investigated. This perseverance was to know how signals are attained by changing amplitude of the sine waves to form a complex time waveform signals. The described fault diagnose technique is beneficial in terms more than $50 \%$ cost of the plant maintenance.

\section{Conflict of Interest}

The authors declare that there is no conflict of interest regarding the publication of this paper. 


\section{References}

[1] Vas, P. 1993. Parameter Estimation, Condition Monitoring, and Diagnosis of Electrical Machines. Oxford: Clarendon Press.

[2] Khan, S. 2011. Simulation and Vibration Analysis of Electrical Machine. Karachi: KANAUP, Pakistan.

[3] Hartog, J. P. D. 1985. Mechanical Vibrations. Dover Publications.

[4] Neha, G., and Pahuja, S. 2012. "Vibration Sensor for Health Monitoring of Electrical Machines in Power Station.” International Journal of Engineering Science and Technology 4 (04 April).

[5] Perrone, G., and Vallan, A. 2009. "A Low-Cost Optical Sensor for Noncontact Vibration Measurements.” IEEE Transactions on Instrumentation and Measurement 58 (5): 1650-6.

[6] Yan, R., and Gao, R. X. 2006. "Hilbert \& Huang Transform-Based Vibration Signal Analysis for Machine Health Monitoring." IEEE Transactions on Instrumentation and Measurement 55 (6): 2320-9.

[7] He, Q., and Wang, X. X. 2012. “Time-Frequency Manifold for Demodulation with Application to Gearbox Fault Detection.” In Proceedings of the IEEE 2012 Prognostics and System Health Management Conference (PHM-2012 Beijing).

[8] Amar, M., Gondal, I., and Wilson, C. 2013. "Fuzzy Logic Inspired Bearing Fault-Model Membership Estimation.” In 2013 IEEE Eighth International Conference on Intelligent Sensors, Sensor Networks and Information Processing.

[9] Goyal, D., and Pabla, B. S. 2016. "Development of Non-contact Structural Health Monitoring System for Machine Tools.” Journal of Applied Research and Technology 14 (4): 245-58.

[10] Mohamed, A. A. et al. 2011. "Monitoring of Fatigue Crack Stages in a High Carbon Steel Rotating Shaft Using Vibration.” Procedia Engineering 10: 130-5.

[11] Huang, H. et al. 2011. "Study on Dynamic Machining Performance of Machine Tool Based on BP Network.” Procedia Engineering 15: 5148-52.

[12] Myhre, B., Petersen, S., and Ugarelli, R. 2014. "Using Wireless Vibration Monitoring to Enable
Condition-Based Maintenance of Rotating Machinery in the Water and Wastewater Industries.” Procedia Engineering 89: 1397-403.

[13] Petersen, S., Myhre, B., and Røstum, J. 2014. "Wireless Instrumentation for the Water and Wastewater Industry.” Procedia Engineering 70: 1314-23.

[14] Mjit, M., Beaujean, P. P. J., and Vendittis, D. J. 2011. "Smart Vibration Monitoring System for an Ocean Turbine.” In 2011 IEEE 13th International Symposium on High-Assurance Systems Engineering.

[15] Dipti Agrawal, M. N. Y., and Suresh, S. 2015. "Condition Monitoring of Slip-ring Induction Motor." International Journal of Innovative Research in Advanced Engineering (IJIRAE) 2 (3).

[16] Siddiqui, K. M., Kuldeep, S., and Giri, V. K. 2014. “A Survey of Health Monitoring and Fault Diagnosis in Induction Motor.” International Journal of Advanced Research in Electrical, Electronics and Instrumentation Engineering 3 (1, January 2014).

[17] Biswal, S., George, J. D., and Sabareesh, G. R. 2016. "Fault Size Estimation Using Vibration Signatures in a Wind Turbine Test-Rig." Procedia Engineering 144: 305-11.

[18] Krishnakumari, A. et al. "Application of Zhao-Atlas-Marks Transforms in Non-stationary Bearing Fault Diagnosis.” Procedia Engineering 144: 297-304.

[19] Ribeiro, L. C. et al. 2014. "Equipment for Predictive Maintenance in Hydrogenerators.” AASRI Procedia 7: 75-80.

[20] Desavale, R. G., and Mali, A. R. 2016. "Detection of Damage of Rotor-Bearing Systems Using Experimental Data Analysis.” Procedia Engineering 144: 195-201.

[21] Helwig, N., Klein, S., and Schütze, A. 2015. "Identification and Quantification of Hydraulic System Faults Based on Multivariate Statistics Using Spectral Vibration Features." Procedia Engineering 120: 1225-8.

[22] Ebersbach, S., and Peng, Z. 2008. "Expert System Development for Vibration Analysis in Machine Condition Monitoring." Expert Systems with Applications 34 (1): 291-9. 